\title{
Application of Machine Learning Methods in Nursing Home Research: Using Fall-Related Data in Nursing Homes
}

\section{Soo-Kyoung Lee}

Keimyung University

Jinhyun Ahn

Jeju National University

juh hyun shin ( $\nabla$ juhshin@ewha.ac.kr)

Ewha Womans University College of Law and Graduate School of Law https://orcid.org/0000-00018058-7195

Ji Yeon Lee

Ewha Womans University

Research article

Keywords: machine learning, accidental falls, nursing homes

Posted Date: August 4th, 2020

DOI: https://doi.org/10.21203/rs.3.rs-21878/v2

License: (c) (i) This work is licensed under a Creative Commons Attribution 4.0 International License. Read Full License 
The authors have withdrawn this preprint from Research Square 